\title{
ANALISIS TRAFFIC PADA JARINGAN LAN MENGGUNAKAN MIKROTIK
}

${ }^{1}$ Dora Sandova, ${ }^{2}$ Cahyo Prihantoro

${ }^{12}$ Universitas Muhammadiyah Bengkulu, Indonesia

Idorasandov@gmail.com; ${ }^{2}$ putraraffless@gmail.com

\section{Article Info}

Article history:

Received, 17/09/2021

Revised, 29/10/2021

Accepted, 27/11/2021

\section{Kata Kunci:}

Jaringan LAN,

Router Mikrotik,

Traffic

\begin{abstract}
ABSTRAK
Jaringan komputer maupun jaringan internet saat ini memiliki peranan penting dalam menjalankan kegiatan sehari-hari, baik dilakukan dalam proses belajar-mengajar, pekerjaan, maupun aktivitas masyarakat. Kendala yang dihadapi salah satunya adalah terkait lalu lintas data yang nantinya akan berkaitan erat dengan kecepatan akses internet. Oleh sebab itu penelitian ini dilakukan untuk menganalisis lalu lintas data (traffic) yang ada dan menemukan pengaturan terbaik untuk mendapatkan hasil yang maksimal dan merata menggunakan perangkat Router Mikrotik. Menggunakan metode pengembangan system NDLC (Network Development Life Cycle). NDLC merupakan model yang mendefinisikan siklus proses perancangan atau pengembangan suatu system jaringan komputer dimana mempunyai elemen yang mendefinisikan fase, tahapan, langkah atau mekanisme proses spesifik. Kesimpulan yang dapat diambil dari evaluasi sistem jaringan ini adalah; Semua Jaringan komputer kabel dapat dimanajemen dengan mikrotik, Pembagian Bandwidth internet dengan mikrotik memberikan efisiensi pemakaian bandwidth internet, Sistem keamanan jaringan yang diberikan oleh mikrotik dapat terfasilitasi dengan baik. Dengan adanya mikrotik, maka dapat diketahui jika adanya PC yang tidak dapat melakukan koneksi atau sedang down. Hasil analisis menunjukkan angka Max in: $675.62 \mathrm{~Kb}$, Average in: $127.08 \mathrm{~Kb}$, Current in: $66.68 \mathrm{~Kb}$, Max Out: $173.88 \mathrm{~Kb}$, Average Out: $24.88 \mathrm{~Kb}$, Current Out: $14.78 \mathrm{~Kb}$.
\end{abstract}

\begin{abstract}
Computer networks and internet networks currently have an important role in carrying out daily activities, whether carried out in the teaching and learning process, work, or community activities. One of the obstacles faced is related to data traffic which will later be closely related to the speed of internet access. Therefore, this study was conducted to analyze the existing data traffic (traffic) and find the best settings to get maximum and even results using a Mikrotik Router device. Using the NDLC (Network Development Life Cycle) system development method. NDLC is a model that defines the process cycle of the design or development of a computer network system which has elements that define a specific phase, stage, step or process mechanism. The conclusions that can be drawn from the evaluation of this network system are; All wired computer networks can be managed with MikroTik, Sharing Internet bandwidth with MikroTik provides efficient use of Internet bandwidth, The network security system provided by MikroTik can be well facilitated. With the proxy, it can be seen if there is a PC that cannot connect or is down. The results of the analysis show Max in: $675.62 \mathrm{~Kb}$, Average in: $127.08 \mathrm{~Kb}$, Current in: $66.68 \mathrm{~Kb}$, Max Out: $173.88 \mathrm{~Kb}$, Average Out: $24.88 \mathrm{~Kb}$, Current Out: $14.78 \mathrm{~Kb}$.
\end{abstract}

\section{Penulis Korespondensi:}

Cahyo Prihantoro,

Program Studi Sistem Informasi,

Universitas Muhammadiyah Bengkulu,

Email:putraraffless@gmail.com 


\section{PENDAHULUAN}

Monitoring jaringan dan analisa data adalah tugas yang sulit dan berat yang merupakan bagian penting dari pekerjaan Administrator Jaringan. Administrator jaringan secara terus-menerus berusaha untuk menjaga kelancaran jaringan [1]. Jika sebuah jaringan mengalami masalah terkait dengan performansi meskipun dengan jangka waktu yang singkat maka sudah dapat dipastikan produktivitas dalam suatu perusahaan akan menurun, dan dalam kasus di departemen layanan publik kemampuan untuk menyediakan layanan sangat penting [2]. Oleh karena itu diperlukan sebuah fasilitas pendukung yaitu sistem monitoring agar administrator dapat me-monitoring jaringan (Rasyid, dkk, 2011) [3].

Salah satu aplikasi monitoring trafik jaringan dengan menggunakan Mikrotik Routerboard. Mikrotik Routerboard merupakan salah satu perangkat keras yang dapat digunakan sebagai router. Sistem operasi tersebut mencakup berbagai fitur lengkap untuk wireline dan wireless, salah satunya adalah monitoring jaringan [4]. Dengan fitur-fitur yang terdapat dalam mikrotik pihak perusahaan dalam hal ini admin dapat me-monitoring dan menganalisa trafik inbound dan outbound sehingga dapat mengantisipasi segala kemungkinan yang dapat mengganggu kinerja dari sebuah jaringan . Adalah fitur tool graph yang dimiliki oleh mikrotik untuk monitoring trafik dimana dengan cara mengaktifkan fitur tersebut admin dapat melihat trafik secara real time [5], ini merupakan masalah yang akan kami teliti.

Rujukan penelitian ini salah satunya adalah pengembangan hasil penelitian dari Galeh Fatma Eko Ardiansa, Rakhmadhany Primananda, Mochammad Hannats Hanafi mahasiswa dari Program Studi Teknik Komputer, Fakultas Ilmu Komputer, Universitas Brawijaya pada tahun 2017 dengan judul jurnal Manajemen Bandwidth dan Manajemen Pengguna pada Jaringan Wireless Mesh Network dengan Mikrotik. Tujuan penelitiannya adalah untuk melakukan monitoring penggunaan internet sesuai dengan manajemen bandwidth dan manajemen pengguna. Metode pengumpulan data yang digunakan adalah metode wawancara (interview), pengamatan (observasi), dan kepustakaan ( library research) [6].

Dalam penelitan ini monitoring trafik dilakukan dengan menggunakan teknik Router Based. Dan tidak hanya trafik yang dapat di-monitor, admin pun dapat me- monitoring dari perangkat tersebut seperti pemblokiran web, aplikasi seperti game, traffic CPU, Disk dan Memory Usage [6].

Berdasarkan uraian pada latar belakang, dapat dirumuskan suatu pokok permasalahan yaitu :

1. Bagaimana managemen jaringan komputer untuk user dalam waktu browsing, upload, download dalam waktu bersamaan agar jaringan komputer normal.

2. Bagaimana cara menerapkan manajement jaringan LAN dengan menggunakan Mikrotik.

3. Bagaimana cara merancang LAN dalam sebuah jaringan dengan mengunakan Mikrotik.

4. Bagaimana cara memblokir website tertentu menggunakan mikrotik.

Adapun batasan masalah yang menjadi batasan antara lain :

1. Sistem jaringan yang menghubungkan antara modem (ISP) dengan computer (client) sebanyak 2 client

2. $\quad$ Penggunaan Winbox sebagai GUI (Graphical User Interface) dalam konfigurasi MikroTik. Penulis hanya berfokus pada pemblokiran situs - situs pornografi dan game online

3. Tipe jaringan yang digunakan Local Area Network (LAN) dan topologi yang dipakai adalah Star.

Tujuannya dari penelitian ini adalah:

1. Semua bagian unit komputer mendapatkan bandwidth sesuai dengan kebutuhan kinerja user.

2 Semua komputer dapat menggunakan internet dengan lancar dan stabil walaupun semua unit komputer menggunakan internet dalam waktu yang bersamaan.

3. Merancang konfigurasi mikrotik pada jaringan pembagian bandwidth, pengaturan proxy, firewall, security, hotspot, dan network management tools

Manfaat Penelitian ini adalah:

1. Pembagian bandwidth yang adil dan stabil kepada client.

2. Mengerti dan memahami cara mengkonfigurasi Mikrotik.

3. Mengerti dan memahami konsep jaringan LAN dapat di implementasikan.

Konsep jaringan berbasis client server [7] juga perlu adanya monitoring bandwidth, begitu juga jika akan dikembangkan lebih lanjut dalam ranah jaringan cloud. Perkembangan saat ini bukan hanya media 
penyimpanan saja yang di-cloud-kan, namun sudah merambah ke ranah infrastruktur perangkat jaringan komputer dan internet [8].

Menyimpulkan bahwa "Manajeman jaringan merupakan kemampuan untuk mengontrol dan memonitor sebuah jaringan komputer dari sebuah lokasi". The International Organization for Standardization (ISO) mendefinisikan sebuah model konseptual untuk menjelaskan fungsi manajemen jaringan, antara lain[9] :

1. Manajemen Kesalahan (Fault Management), ditujukan agar administrator dapat mengetahui kesalahan (fault) pada perangkat, sehingga dapat diambil tindakan perbaikan.

2. Manajemen Konfigurasi (Configuration Management), mencatat informasi konfigurasi jaringan, sehingga dapat dikelola dengan baik.

3. Pelaporan (Accounting), mengukur penggunaan jaringan dari pengguna.

4. Manajemen Performa (Performance Management), mengukur performansi jaringan dan melakukan pengumpulan dan analisis data statistik.Manajemen Keamanan (Security Management), mengatur akses ke resource jaringan sehingga informasi tidak dapat diperoleh tanpa izin [10], [11].

Berdasarkan latar belakang masalah tersebut di atas, tentang monitoring trafik internet untuk optimasi pengguanaan bandwidth terutama pada layanan data internet maka peneliti berfokus pada teknik konfigurasi router untuk monitoring traffic sebagai solusi dari permasalahan yang ada. Tentu dengan cara mengaktifkan fitur yang tersedia para mikrotik routerboard dan mengoptimalkan settingannya untuk performas yang baik.

\section{METODE PENELITIAN}

\section{Rancangan Analisis}

Pendefinisian umum mengenai tahapan dan alur proses, elemen-elemen yang ada, dalam penelitian ini, penulis menggunakan metode pengembangan system NDLC (Network Development Life Cycle). $N D L C$ merupakan model yang mendefinisikan siklus proses perancangan atau pengembangan suatu system jaringan komputer. $N D L C$ mempunyai elemen yang mendefinisikan fase, tahapan, langkah atau mekanisme proses spesifik. Kata Cycle merupakan kunci deskriptif dari siklus hidup pengembangan system jaringanyang menggambarkan secara keseluruhan proses dan tahapan pengembangan system jaringan yang berkesinambungan.

(sumber : TIPHON [12])

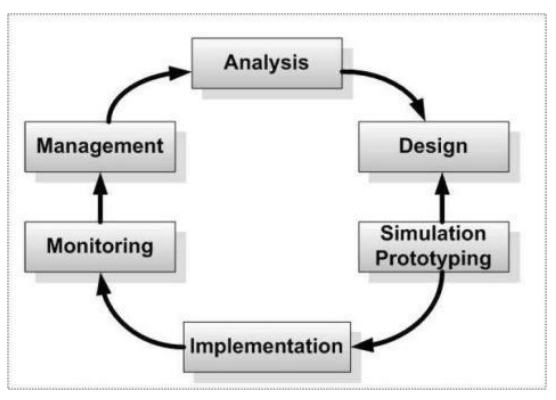

Gambar 1. Rancangan Analisis

\section{Topologi Jaringan}

Topologi jaringan merupakan hal yang paling mendasar dalam membentuk sebuah jaringan, untuk topologi jaringan yang digunakan yaitu Topologi Star, mudah pemasangan jaringannya karena tiap komputer menggunakan satu kabel jaringan apabila satu komputer ada yang rusak maka jaringan komputer yang lain tidak terganggu. Topologi star mengutamakan komputer server sebagai pusat kontrol. Hal ini menyangkut fungsi dan efisiensi dalam penyimpanan dan pengolahan data sehingga dapat terkontrol dengan baik dan lancer [13]. 


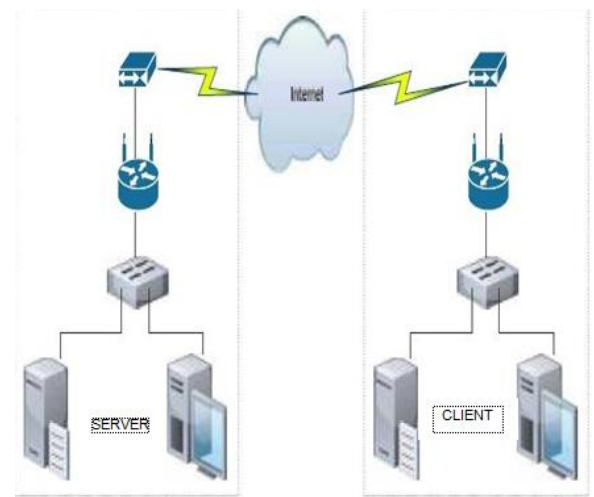

Gambar 2. Topologi Jaringan Star

\section{Permasalahan Sistem Jaringan}

Dari hasil penelitian yang dilakukan, permasalahan pokok yang menjadi masalah ialah belum adanya router MikroTik sehingga belum diterapkannya.

Beberapa permasalahan yang sering dihadapi, yaitu:

1. Penyalahgunaan bandwidth untuk mengakses situs-situs yang tidak ada hubungannya dengan pekerjaan.

2. Jumlah bandwidth yang diperoleh antar pengguna tidak seimbang.

3. Sulitnya pada saat melakukan proses download maupun upload data saat pemaikaian bersamaan.

Tidak adanya pembagian bandwidth menyebabkan koneksi beberapa client terasa lambat. Apalagi banyak keperluan yang tidak sama antara satu dengan yang lain, ada yang mengunduh dan ada juga yang browsing ataupun mengirim email dan biasanya menghabiskan bandwidth dan akhirnya internet menjadi lambat [14].

Active Monitoring diperlukan untuk melihat dan memantau arus lalu lintas data. Monitoring ini sangat membantu untuk menentukan waktu latensi antara dua perangkat pada jaringan pada area yang luas, serta tugas yang lebih kompleks seperti pengumpulan pengukuran untuk memastikan kualitas layanan (QoS) tercapai. Hal ini berguna bagi admin yang menginginkan data pada aspek kinerja jaringan tertentu [15], [16].

Sistem secara aktif mengukur parameter seperti :

1. Availability / Tersedianya

2. Routes / rute

3. Packet Delay

4. Packet Reordering

5. Packet Loss

6. Packet Inter-Arrival Jitter

7. Bandwidth Measurments (Capacity, Achievable Throughputs)

Perintah yang biasa digunakan seperti ping, untuk mengukur delay dan loss paket. Dan traceroute yang membantu menentukan hop data dalam sebuah topologi jaringan, adalah contoh dari perintah dasar yang sering digunakan. Ping dan Traceroute mengirim paket ICMP (probe) ke host yang ditunjuk dan menunggu host merespon kembali ke pengirimnya. Perintah ping yang menggunakan active monitoring dengan mengirim permintaan Echo dari host sumber melalui jaringan ke tujuan yang ditentukan. Tujuan kemudian mengirimkan Respons Echo kembali ke sumber itu tersebut [17].

\section{HASIL DAN ANALISIS}

\section{a) Konfigurasi Mikrotik}

\section{Konfigurasi Awal dan Pengaturan IP}

Untuk mengkonfigurasi mikrotik pada awal pemakaian di PC router, dapat digunakan terminal login CLI (command line interface). Tetapi selain setting CLI (command line interface) dapat juga menggunakan langsung setting via winbox dan untuk mendapatkan winbox Anda sudah 
dapat mengakses PC router mikrotik dengan menggunakan web browser dan memasukkan address http://192.168.88.1. IP ini didapat dari IP default mikrotik yang tertera.

Setelah winbox dijalankan, maka isi IP router 192.168.1.1 denganlogin "admin" dan password, lalu klik tombol Connect.

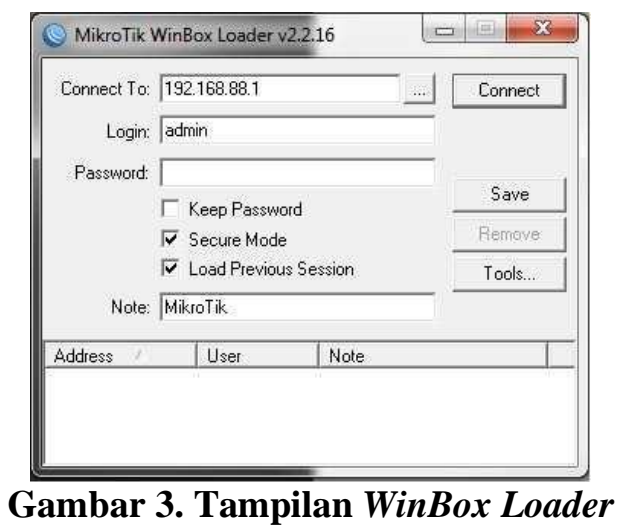

\section{Setting NAT IP}

NAT (Network Address Translation) pada gateway mikrotik belum diaktifkan. Network Address Translation atau yang lebih biasa disebut dengan NAT adalah salah satu fasilitas router untuk meneruskan paket dari IP asal ke IP tujuan. Jadi semua komputer client terhubung dengan jaringan internet menggunakan IP publik router 120.29.150.162 Tanpa NAT, seluruh computer client tidak dapat terhubung dengan public network. Untuk mengaktifkan NAT yaitu dengan cara mengklik IP » Firewall » tab NAT» + (Add), di New NAT Rule tab General, masukkan output interface Biznet. Kemudian klik tab Action, Action: masquerade, dan OK.
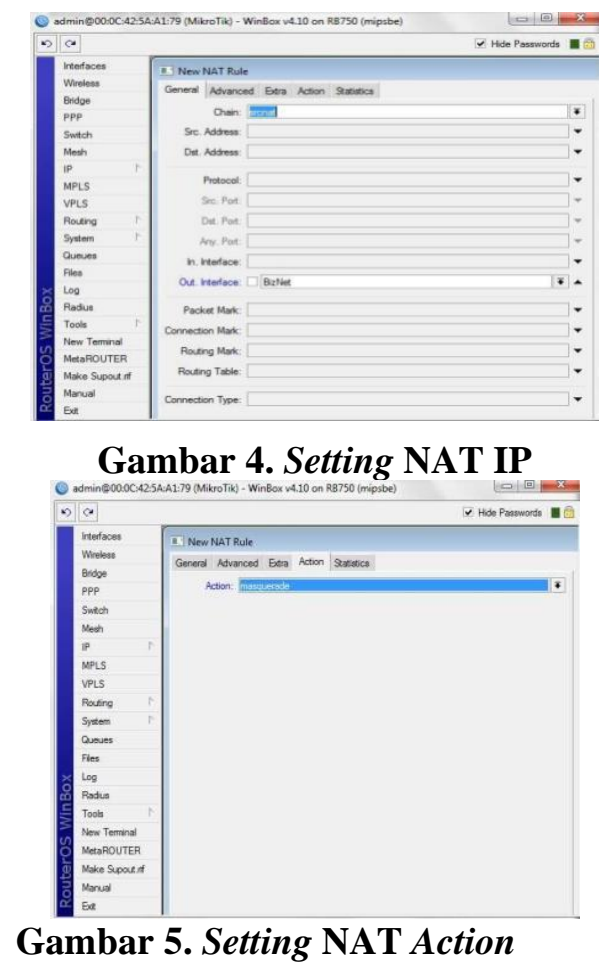

\section{Filter Mac Address dan IP Address}

Secara garis besar filtering ini dilakukan untuk menghindari penyusup terutama dalam local area network.. Selain itu filtering ini juga dapat dilakukan pada mikrotik. Jadi apabila mac address dan IP address yang tidak terdaftar dalam rules mikrotik, maka komputer tersebut tidak dapat mengakses mikrotik dan internet. 
Hal ini juga berlaku pada komputer client, apabila mac address tidak sama dengan IP address yang telah diatur dalam rules mikrotik, maka komputer client juga tidak dapat mengakses mikrotik dan internet. Konfigurasinya: $\boldsymbol{I P} \gg \boldsymbol{A R P}$, Setiap PC yang memakai kabel atau wireless akan terdeteksi di ARP list. address list, konfigurasinya: IP " Firewall 》 Address List " (+)Add. Masukkan semua IP yang telah terdaftar untuk menggunakan internet.

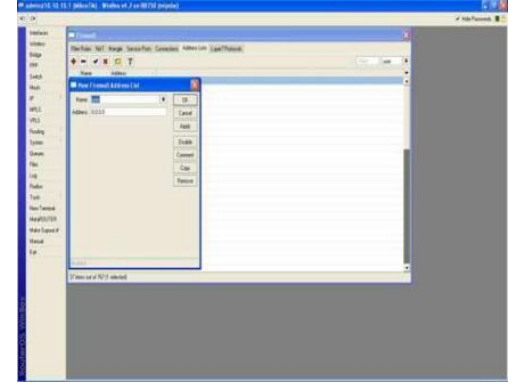

\section{4. $\quad$ Filter Rule}

\section{Gambar 6. Filter Mac Address dan IP Address}

Setelah IP sudah dilist, kemudian buat rule atau aturan, agar setiap IP bisa diidentifikasi dan juga setiap IP baru yang masuk tidak bisa langsung mengakses internet. Konfigurasinya: IP » Firewall » Filter Rules » (+)Add. Didalam layar add "General: isi Chain Forward Advance: isi Scr Address dengan! user ( nama inisialisasi di Address List) » Action: isi dengan drop. Hal ini mengartikan bahwa selain kelompok IP user tidak dapat mengakses internet.

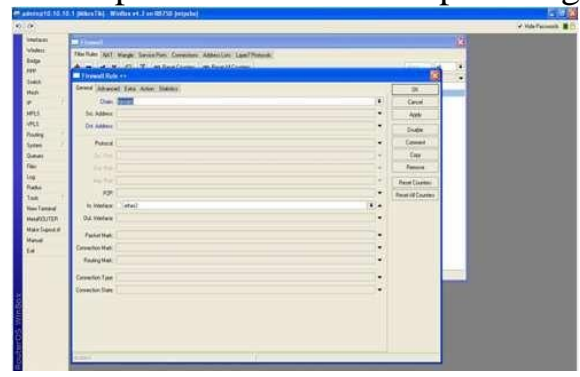

\section{Pengaturan Bandwidth}

\section{Gambar 7. Filter Rule}

Membatasi penggunaan bandwidth untuk masing-masing client bertujuan agar tidak ada satupun client yang akan memonopoli penggunaan bandwidth. Dalam pengaturan Bandwidth Download Dan Upload, konfigurasinya: Buka Winbox » Queues » Klik Simple Queues » Add » isi max bandwidth limit pada tab general " dan isi minimal bandwidth (limit At) pada tab advance.

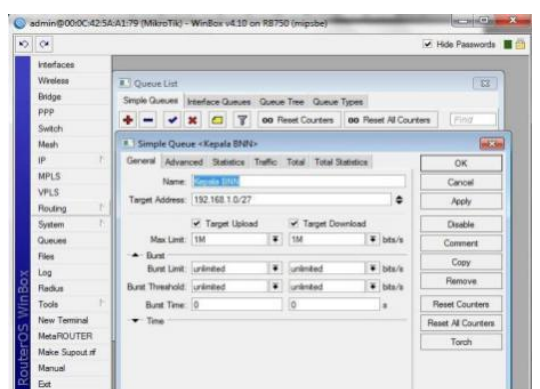

\section{Gambar 8. Tampilan Maximal Bandwidth}

Untuk parameter bandwidth, implementasi Mikrotik pada LAN yaitu mengendalikan traffic jaringan dengan melakukan management bandwidth sistem HTB (Hierarchical Token Bucket) jenis simple quee. Pada metode management bandwidth jenis simple quee ini administrator dapat membatasi bandwidth maximum yang dapat digunakan oleh tiap klien, sehingga klien dapat saling meminjam bandwidth jaringan selama bandwidth total yang digunakan oleh klien tidak melebihi nilai yang dialokasikan kepadanya, jika melewati maka klien tidak diijinkan meminjam bandwidth jaringan. 
JSAI : Journal Scientific and Applied Informatics

Vol. 4, No. 3, November 2021, hal. 329 337

E-ISSN: 2614-3054; P-ISSN: 2614-3062, Terakreditasi Kemenristekdikti, Sinta 5

\begin{tabular}{|l|l|l|l|}
\hline no & Nama Perangkat & $\begin{array}{c}\text { Kapasitas } \\
\text { Bandwidth } \\
(\mathrm{kbps})\end{array}$ & $\begin{array}{c}\text { Bandwidth } \\
\text { Tersedia } \\
(\mathrm{kbps})\end{array}$ \\
\hline 1 & N Laboratorium & 1000022 & 52200 \\
\hline 2 & N Tata Usaha & 1000022 & 65500 \\
\hline 2 & N Perpustakaan & 1000022 & 69600 \\
\hline
\end{tabular}

Dari hasil pengukuran yang telah dilakukan dapat dilihat perbandingan kapasitas bandwidth yang dimiliki oleh tiap client dengan bandwidth tersedia yang didapat oleh client seperti pada table 1 . Bandwidth yang tersedia berada dibawah kapasitas bandwidth yang disediakan, hal ini bisa disebabkan karena alokasi bandwidth untuk klien dibatasi dengan maximum bandwidth $128 \mathrm{~kb}$, hal ini dapat mempengaruhi Kualitas layanan suatu jaringan karena semakin besar kapasitas bandwidth yang dialokasikan maka semakin besar pula bandwidth yang tersedia.

Monitoring dengan Graphing Sebagai network admin tentunya ingin mengetahui apakah traffic yang berjalan di jaringan sudah sesuai dengan semestinya. Caranya yaitu dengan menggunakan monitoring traffic pada mikrotik yang disebut sebagai graphing.

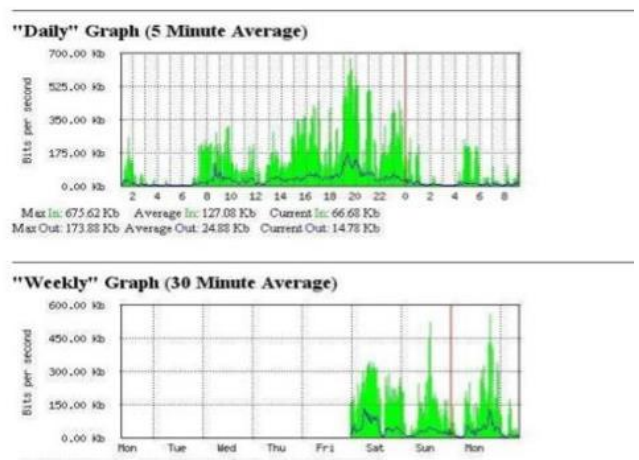

\section{Gambar 9. Network Monitoring Tools Mikrotik}

\section{Mikrotik Web Proxy Blokir Website}

Salah satu fungsi proxy adalah untuk menyimpan cache dan memblok alamat-alamat situs. Dalam hal ini proxy hanya digunakan untuk memblok situs-situs internet, yang tidak diperlukan. Konfigurasinya: IP » Web proxy » (+) Add: isi dst. Host dengan nama situs yang akan diblok» Kemudian klik web proxy setting dan checklist pada Enable.

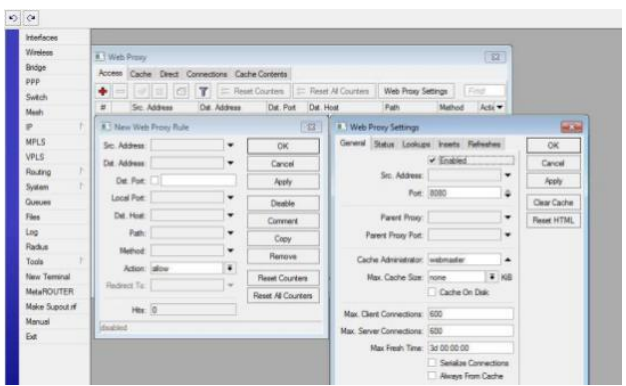

\section{Gambar 10. Setting Web Proxy}




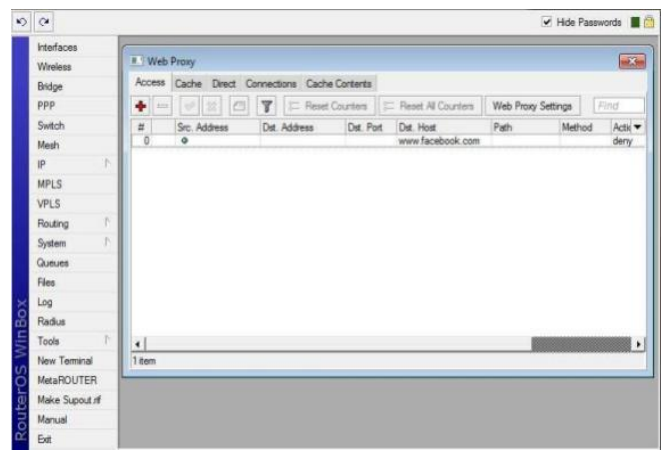

Gambar 11. Web Proxy

Pertama konfigurasi mikrotik menggunakan winbox. Mengatur ip pada setiap ether pada mikrotik dan juga default gateway pada mikrotik.

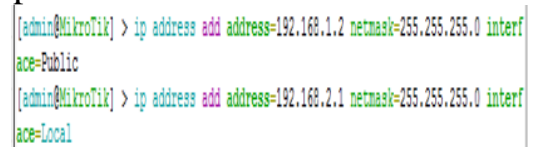

Gambar 12. Mengatur IP setiap ether

[admindVirotik] > in moute add gateway=192,168,1,1

Gambar 13. Mengatur default gateway pada mikrotik

Setelah itu mengatur DNS pada mikrotik dan juga firewall agar client terhubung ke internet.

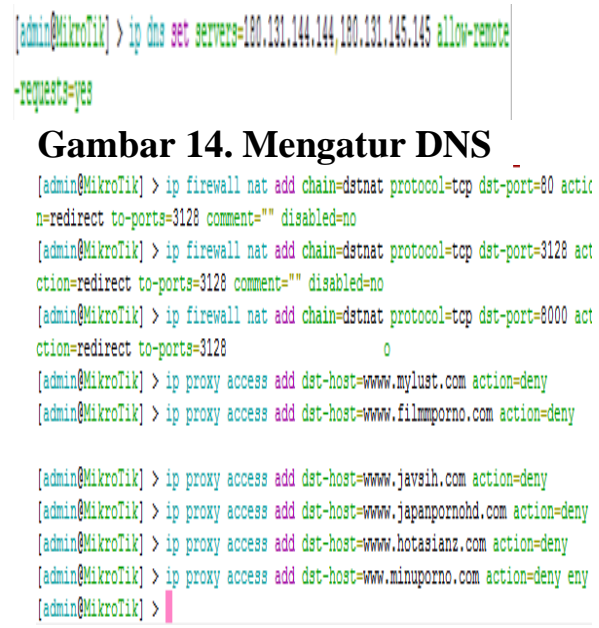

\section{Gambar 15. Mengatur proxy}

Setelah semua dikonfigurasi, maka situs yang sudah di blokir akan memiliki tampilan seperti ini.

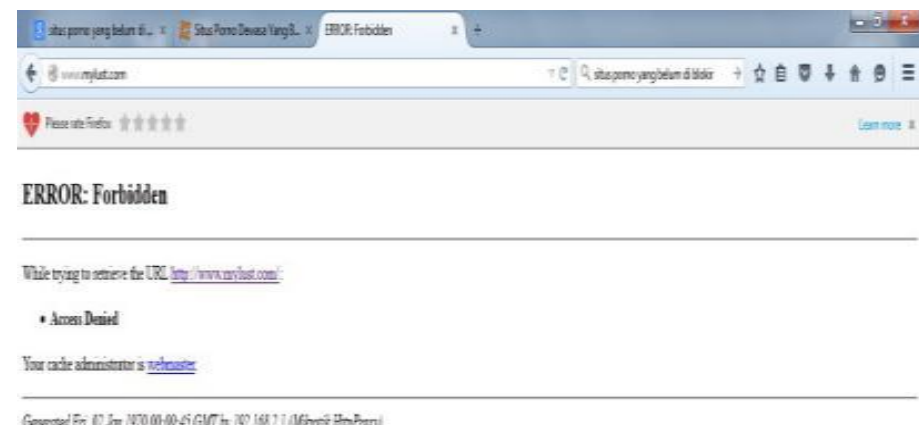

Gambar 16. Tampilan Halaman Website yang diblokir 


\section{KESIMPULAN}

Kesimpulan yang dapat diambil dari evaluasi sistem jaringan ini adalah; Semua Jaringan komputer kabel dapat dimanajemen dengan mikrotik, Pembagian Bandwidth internet dengan mikrotik memberikan efisiensi pemakaian bandwidth internet, Sistem keamanan jaringan yang diberikan oleh mikrotik dapat terfasilitasi dengan baik. Dengan adanya mikrotik, maka dapat diketahui jika adanya PC yang tidak dapat melakukan koneksi atau sedang down. Hasil analisis menunjukkan angka Max in: $675.62 \mathrm{~Kb}$, Average in: $127.08 \mathrm{~Kb}$, Current in: $66.68 \mathrm{~Kb}$, Max Out: $173.88 \mathrm{~Kb}$, Average Out: $24.88 \mathrm{~Kb}$, Current Out: $14.78 \mathrm{~Kb}$.

\section{REFERENSI}

[1.] Binanto, Iwan. 2017. Membangun Jaringan Komputer. Yogyakarta: Graha Ilmu.

[2.] Dhanta, Rizky. 2009. Pengantar Ilmu Komputer. Surabaya: Indah.

[3.] Rasyid, B.A., Solikin dan Sularsa, A., 2011, Realisasi Monitoring Server Menggunakan Nagios Dengan Memanfaatkan Event Handler, email dan SMS Gateway, ACADEMIA Politeknik Telkom, edisi September 2011, Lembaga Penelitian Politeknik Telkom, Bandung

[4.] Daulay, Melwin Syafrizal. 2017. Mengenal Hardware Software dan Pengelolaan Instalasi Komputer. Yogyakarta: Andi.

[5.] Listanto, Virgiawan. 2019. Teknik Jaringan Komputer. Jakarta: Prestasi Pustaka. Sofana, Iwan. 2018. Cisco CCNA dan Jaringan Komputer. Bandung: Informatika Yani, Ahmad. 2019. Jaringan Komputer. Jakarta: Kawan Pustaka.

[6.] Hardana \& Ino Irvantino, 2017, “Konfigurasi Wireless Routerboard Mikrotik”, Penerbit Andi, Yogyakarta.

[7.] Prihantoro, C., \& Witriyono, H. (2019). Perancangan Client Server Three Tier Pada Pembangunan Web Service Anggota Perpustakaan Universitas Muhammadiyah Bengkulu. Journal of Technopreneurship and Information System (JTIS), 2(2), 68-73.

[8.] Prihantoro, C., \& Witriyono, H. (2017). IMPLEMENTASI SKALA MINIMUM CLOUD COMPUTING KATEGORI SOFTWARE AS A SERVICE (SAAS) PADA INSTITUSI PERGURUAN TINGGI (Studi Kasus: Unit Pelayanan Terpadu Teknologi Informasi dan Komunikasi Universitas Muhammadiyah Bengkulu-UPT TIK UMB). Pseudocode, 4(2), 129-136.

[9.] Fatoni. (2017). Analisis Quality of Service $(Q o S)$ Jaringan Local Area Network pada Universitas Bina Darma, Jurnal Magister Teknik Informatika Universitas Binadarma Palembang.

[10.] Kamarullah, A. Hafiz. (2016). Penerapan Metode QoS pada Jaringan Traffic yang Padat, Jurnal Jaringan Komputer Universitas Sriwijaya.

[11.] Mitra, Aditya Rama dan Sherly Mariana. (2019). Analisis dan Penerapan Quality of Service dengan Pembagian Bandwidth Berdasarkan Port Pada Jaringan WiFi UPH, Jurnal Program Studi Teknik Komputer Universitas Pelita Harapan.

[12.] Etsi. (2018). Telecommunication and Internet Protocol Harmonization Over Network (TIPHON) General aspect of Quality of Service (QoS).

[13.] O. Shimonski, The Wireshark Field Guide : Analyzing and Troubleshooting Network Traffic, Syngress, 2019.

[14.] Anagnostakis, K.G.; Ioannidis, S. ; Miltchev, S. ; Greenwald, M. ; Smith, J.M. (University of Pennsylvania), "Efficient

[15.] Packet Monitoring for Network Management" Proceedings of the 8th IEEE/IFIP Network Operations and Management Symposium (NOMS), 2002

[16.] Cisco Systems, "Simple Network Management Protocol", Internetworking Technologies Handbook, Chpt 56, 1992-2006

[17.] Orebaugh, A. et al. Wireshark \& Ethereal Network Protocol Analyzer Toolkit, Syngress Publishing, 2006 